for the CC bond rotations in the allyl cation ${ }^{33}$ and 1,1,2-trimethylallyl cation, ${ }^{34} 34.9$ and $11.7 \mathrm{kcal} / \mathrm{mol}$, respectively, indicate that the conjugative overlap between the $\pi$-electrons and the vacant boron p-orbital in the vinylboranes is significantly smaller.

Table V summarizes the computed geometries and chemical shifts for methyl-substituted vinylboranes. The introduction of the second methyl group in $\mathbf{1 2}$ strongly affects the chemical shift of the vinylic $\beta$-carbon, which is shielded by more than $10 \mathrm{ppm}$ with respect to the monomethyl derivative 6 . However, the $\delta^{13} \mathrm{C}$ chemical shift computed for $\mathrm{C}_{\beta}$ of $12,146.6 \mathrm{ppm}$, still shows an unusually large deviation from the experimental value (135.8 ppm). Obviously, $\delta{ }^{13} \mathrm{C}_{\beta}$ is rather susceptible to perturbations of the $\pi$-electron distribution induced by substituents. E.g., attachment of an alkyl substituent to the $\beta$-carbon results in a downfield shift for $\delta^{13} \mathrm{C}$; see 7 in Table IV, $178.2 \mathrm{ppm}$; a comparable experimental example may be methyl-2-borolene: ${ }^{35}$

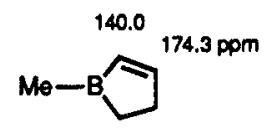

\section{Conclusions}

The barrier for the $[1,3]$ sigmatropic boron shift in dialkylallylboranes is reasonably well-described by theory, but the alkyl

(33) Ab initio calculations: Raghavachari, K.; Whiteside, R. A.; Pople, J. A.; Schleyer, P. v. R. J. Am. Chem. Soc. 1981, 103, 5649.

(34) Experiment, probably very similar to 1,1-dimethylallylborane: Bollinger, J. M.; Brinich, J. M.; Olah, G. A. J. Am. Chem. Soc. 1970, 92, 4025

(35) Herberich, G. E.; Boveleth, W.; Hessner, B.; Hostalek, M.; Köffler. D. P.; Ohst, H.; Söhnen, D. Chem. Ber. 1986, 119, 420. groups on boron have an important influence. The parent allylborane would be expected to have greater fluxional character (with a barrier less than $2 \mathrm{kcal} / \mathrm{mol}$ ). Cyclic isomers with nonclassical structures (e.g., 2) may actually be favored.

A comparison of other chemically relevant $\mathrm{C}_{3} \mathrm{BH}_{7}$ isomers to their isoelectronic $\mathrm{C}_{4} \mathrm{H}_{7}{ }^{+}$counterparts generally reveals the same structural influences to be important for both classes of compounds. However, the electronic effects are larger in magnitude for the carbocations, as reflected in a higher inversion barrier for the bicyclobutonium ion and the higher rotation barrier for the cyclopropylcarbinyl cation (relative to their boron counterparts).

The NMR chemical shifts we predicted at an adequate level of sophistication (IGLO TZP basis set for MP2/6-31G* geometries) should be reliable. Comparison with experimentally accessible derivatives usually gives a good agreement of theory and experiment. One exception is the ${ }^{13} \mathrm{C}$ chemical shift of the vinylic $\beta$-carbon in vinylboranes which proves to be very sensitive to the influence of directly bound and remote substituents.

Acknowledgment. This work was supported by the Fonds der Chemischen Industrie, the Stiftung Volkswagenwerk, and the Convex Computer Corporation. We thank Professor W. Kutzelnigg and Dr. M. Schindler for the Convex version of their IGLO program. M.B. gratefully acknowledges a grant from the Studienstiftung des deutschen Volkes. The calculations were performed on a CONVEX C210 at the Institut für Organische Chemie, a Cyber 995e at the Regionales Rechenzentrum Erlangen, and a CRAY YMP-8/42 at the Leibniz Rechenzentrum München.

\title{
Elucidation of the Conformational Properties of $N$-Formylglycine Dithio Acid by ab Initio SCF-MO Calculations
}

\author{
R. Fausto, ${ }^{\dagger}$ J. J. C. Teixeira-Dias, ${ }^{*, \dagger}$ and P. R. Carey ${ }^{\ddagger}$ \\ Contribution from The University Chemical Department, P-3049 Coimbra, Portugal, and \\ National Research Council of Canada, Institute for Biological Sciences, Ottawa, \\ Canada KIA OR6. Received July 23, 1990
}

\begin{abstract}
Ab initio SCF-MO calculations were carried out for the molecule $N$-formylglycine dithio acid using STO-3G and 3-21G basis sets. Structures and energies of several conformations of this molecule determined by gradient geometry refinement are reported, and some conformationally dependent local geometry trends discussed. For conformations involving rotational isomerism about the $\mathrm{NH}-\mathrm{CH}_{2}$ and $\mathrm{CH}_{2}-\mathrm{C}(=\mathrm{S})$ single bonds, the 3-21G results reveal the presence of three conformational states. These conformers are strikingly similar to those determined for glycine dithio esters by X-ray crystallographic and vibrational spectroscopic analyses. One conformer has a small $\mathrm{NH}-\mathrm{CH}_{2}-\mathrm{C}-\mathrm{S}_{(\text {thiol) }}$ torsional angle and close $\mathrm{N}-$ to $-\mathrm{S}_{(\text {thiol }}$ atom contact. The calculations provide a description of this N...S nonbonded interaction which has implications for the structure and reactivity of enzyme-substrate complexes which incorporate a similar contact. However, no evidence is found for favorable $\mathrm{N}$-to- $\mathrm{S}_{(\text {thiono) }}$ interactions for the conformer which has a small $\mathrm{NH}-\mathrm{CH}_{2}-\mathrm{C}=\mathrm{S}$ torsional angle.
\end{abstract}

\section{Introduction}

Resonance Raman (RR) spectroscopy can provide the vibrational spectrum associated with the bonds undergoing catalytic transformation in enzyme-substrate complexes of the type RC$(=0) \mathrm{NHCHR}^{\prime} \mathrm{C}(=\mathrm{S}) \mathrm{S}$-enzyme, where the enzyme is a member of the cysteine protease family, ${ }^{1-3}$ For this kind of reaction intermediate, the chromophore used to generate the RR spectrum is based on the dithio group, $-\mathrm{C}(=\mathrm{S}) \mathrm{S}-$. Obtaining the maximum amount of chemical information from the RR data

* Author to whom correspondence should be addressed.

the University Chemical Department.

t National Research Council of Canada. requires a detailed knowledge of the interrelationship between $R R$ spectral features and conformational states within the $-\mathrm{C}(=$ O) $\mathrm{NHCHR}^{\prime} \mathrm{C}(=\mathrm{S}) \mathrm{SCH}_{2}-$ moiety. Thus, conformational analysis of model compounds, e.g., glycine-based $\left(R^{\prime}=H\right)$ dithio esters and acids, and the setting up of spectra-structure correlations has gone hand in hand with RR studies of the enzyme complexes. Conformational analysis of the "model" dithio esters has been undertaken with use of IR, Raman, and RR vibrational

(1) Storer, A. C.; Murphy, W. F.; Carey, P. R. J. Biol. Chem. 1979, 254, 3163 .

(2) Carey, P. R.; Storer, A. C. Acc. Chem. Res. 1983, 16, 455.

(3) Lowe, G.; Williams, A. Biochem. J. 1965, 96, 189. 
spectroscopic techniques. ${ }^{4,6}$ In addition, combined Raman and X-ray crystallographic studies of single crystals of selected glycine dithio esters ${ }^{79}$ have provided detailed starting points for correlating RR spectra and structure.

For $\mathrm{N}$-acylglycine dithio esters the spectra-structure correlations generated for the model compounds provide a good basis for interpreting the RR spectra of the corresponding $\mathrm{N}$-acylglycine dithioacyl enzymes. It was found ${ }^{9-12}$ that the conformation of the bound substrate is in a so-called B state in which, as a consequence of a small $\left(\approx 20^{\circ}\right) \mathrm{NH}-\mathrm{CH}_{2}-\mathrm{C}-\mathrm{S}_{(\text {thiol })}$ torsional angle, the $\mathrm{N}$ and $\mathrm{S}_{(\text {thiol) }}$ atoms are in close contact. However, there remain a number of discrepancies between the enzyme-substrate RR spectra and the spectra of corresponding model compounds which can only be understood if a more detailed theoretical analysis is undertaken. In addition, the chemistry of the $\mathrm{N} \cdots \mathrm{S}_{(\text {thiol })}$ contact found in the active site, and in B conformers of model compounds, has never been described at the quantum mechanical level. More recently, the conformational properties of $N$-acylalanine dithioacyl enzymes, $\mathrm{RC}(=\mathrm{O}) \mathrm{NHCH}\left(\mathrm{CH}_{3}\right) \mathrm{C}(=\mathrm{S}) \mathrm{S}$-papain, have been shown to be quite different from those of glycine intermediates. ${ }^{13,14}$ The existence of these non-B-type acyl conformers restarts questions as to the effect, if any, of the $\mathrm{N}$... $\mathrm{S}_{(\text {thiol })}$ contact on the kinetic properties of glycine-based dithioacyl papains whose acyl groups are in the B conformation.

The present work explores the use of ab initio SCF methodology to define the conformational states of $\mathrm{HC}(=\mathrm{O}) \mathrm{NHCH}_{2} \mathrm{C}(=$ S)SH. Recently, systematic ab initio SCF-MO calculations on sulfur- or oxygen- and nitrogen-containing molecules ${ }^{15-21} \mathrm{dem}$ onstrated the reliability of such a type of studies to perform conformational analysis and to determine equilibrium geometries, electric dipole moments, charge distributions, and relative energies. Good agreement was obtained between experimental and theoretical results with use of the split valence $3-21 \mathrm{G}$ basis set. ${ }^{22,23}$ The latter uses a linear combination of three primitive Gaussian functions for inner-shell representation and has its valence shell functions split into two and one Gaussian functions, respectively. While this basis contains the same number of primitives as the widely used STO-3G minimal basis set, ${ }^{24,25}$ it comprises almost

(4) Storer, A. C.; Ozaki, Y.; Carey, P. R. Can. J. Chem. 1982, 60, 199.

(5) Lee, H.; Storer, A. C.: Carey, P. R. Biochemistry 1983, 22, 4781.

(6) Carey, P. R.; Storer, A. C. Pure Appl. Chem. 1985, 57, 225.

(7) Huber, C. P.; Ozaki, Y.; Pliura, D. H.; Storer, A. C.; Carey, P. R. Biochemistry 1982, 2l, 3109.

(8) Varughese, K. I.; Storer, A. C.; Carey, P. R. J. Am. Chem. Soc. 1984, 106,8252 .

(9) Huber, C. P.; Carey, P. R.; Hsi, S.-C.; Lee, H.; Storer, A. C. J. Am. Chem. Soc. 1984, 106, 8263 .

(10) Storer, A. C.; Lee, H.; Carey, P. R. Biochemistry 1983, 22, 4789.

(11) Ozaki, Y.; Pliura, D. H.; Carey, P. R.; Storer, A. C. Biochemistry 1982, 21,3102 .

(12) Carey, P. R.; Lee, H.; Ozaki, Y.; Storer, A. C. J. Am. Chem. Soc. 1984, 106, 8258

(13) Storer, A. C.; Angus, R. H.: Carey, P. R. Biochemistry 1988, $27,264$.

(14) Angus, R. H.; Lee, H.; Storer, A. C.; Carey, P. R. Biochemistry 1988, 27,258

(15) Fausto, R.; Teixeira-Dias, J. J. C.; Carey, P. R. J. Mol. Struct. (Theochem.) 1987, 152, 119.

(16) Fausto, R.; Teixeira-Dias, J. J. C. J. Mol. Struct. (Theochem.) 1987, 150, 381 .

(17) Fausto, R.: Batista de Carvalho, L. A. E.; Teixeira-Dias, J. J. C.; Ramos, M. N. J. Chem. Soc. Faraday Trans. II 1989, 86, 1945.

(18) Fausto, R. Ph. D. Thesis, The University Chemical Department, P-3049 Coimbra, Portugal, 1987.

(19) Fausto, R.; Teixeira-Dias, J. J. C.; Ramos, M. N. Spectrochim. Acta $1988,44 A, 47$

(20) Batista de Carvalho, L. A. E.; Amorim da Costa, A. M.; Leonor Duarte, M.: Teixeira-Dias, J. J. C. Spectrochim. Acta 1988, A44, 723.

(21) Batista de Carvalho, L. A. E.; Amorim da Costa, A. M.; TeixeiraDias, J. J. C. J. Mol. Struct. (Theochem.) In press.

(22) Binkley, J. S.; Pople, J. A.; Hehre, W. J. J. Am. Chem. Soc. 1980, 102,939 .

(23) Gordon, M. S.; Binkley, J. S.; Pople, J. A.; Pietro, W. J.; Hehre, W. J. J. Am. Chem. Soc. 1982, 104, 2797.

(24) Hehre, W. J.; Stewart, R. F.; Pople, J. A. J. Am. Chem. Soc. 1969. $51,2657$.

(25) Hehre, W. J.; Ditchfield, R.; Stewart, R. F.; Pople, J. A. J. Am. Chem. Soc. 1970, 52, 2769.

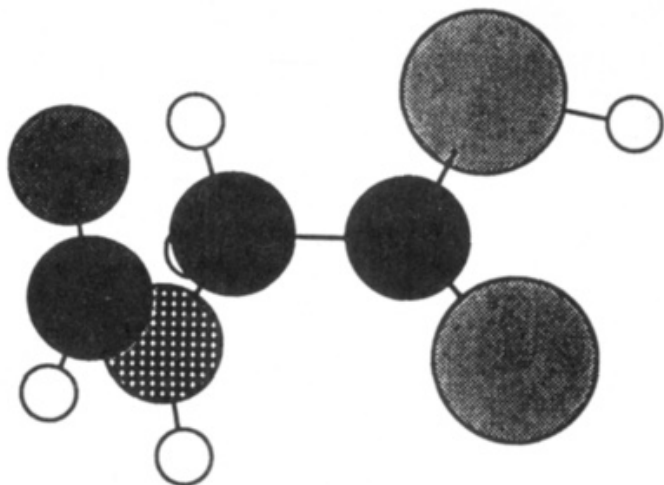

ค
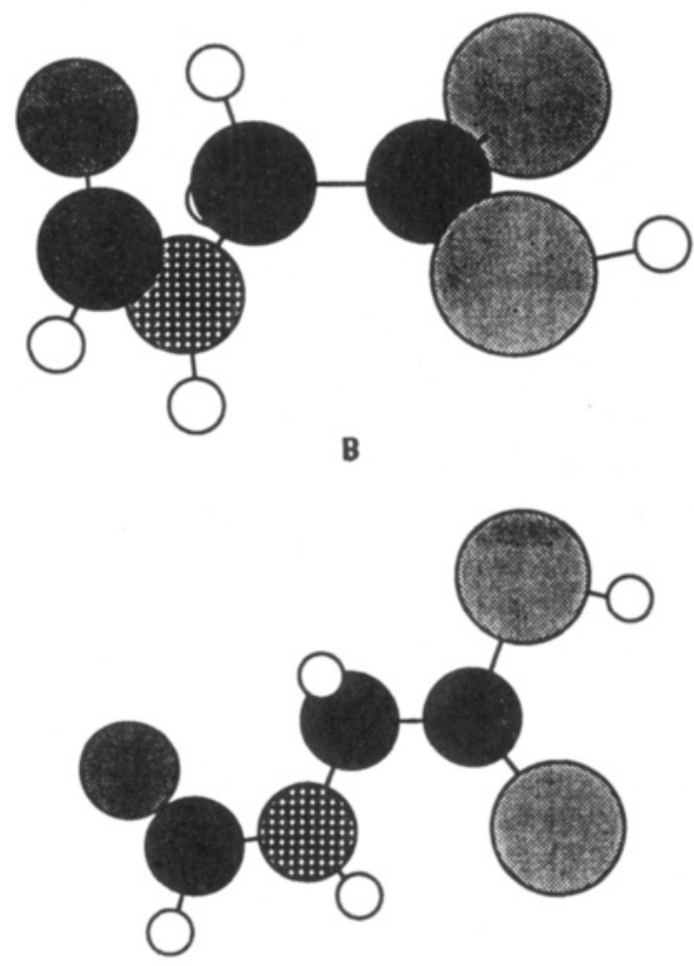

C5

Figure 1. 3-21G calculated conformers of $N$-formylglycine dithio acid: open circles $=\mathrm{H}$, black $=\mathrm{C}$, large gray $=\mathrm{S}$, small gray $=\mathrm{O}$, stippled $=\mathrm{N}$.

twice the number of basis functions per atom ( 2 for hydrogen, 9 for carbon, nitrogen, and oxygen, and 13 for sulfur vs 1.5 and 9 basis functions, respectively, for the minimal set). Thus, it allows a good compromise between the quality of results and computer time requirements.

For the molecule discussed here, $\mathrm{HC}(=\mathrm{O}) \mathrm{NHCH}_{2} \mathrm{C}(=\mathrm{S}) \mathrm{SH}$, the results using the 3-21G basis set show remarkable agreement with the conformational properties delineated by using vibrational spectroscopic and crystallographic analysis of related dithio esters. The ab initio approach correctly predicts the existence of A- and B-type conformers (Figure 1), which have been detected by crystallographic studies on a number of $\mathrm{N}$-acylglycine dithio esters. $^{7-9}$ The calculations also confirm the existence of a $\mathrm{C}_{5}$-type conformer (Figure 1), which has been postulated on the basis of FTIR analysis. ${ }^{9}$ For the B-type conformer, the insight provided by the $\mathrm{ab}$ initio calculations into the $\mathrm{N}$... $\mathrm{S}_{(\text {thiol) }}$ contact is important since, as discussed in detail in ref 26 , this interaction may indeed modulate the rate constant for deacylation of acylpapains involving glycine-based acyl groups. ${ }^{12}$

\section{Computational Methods}

The ab initio SCF-MO calculations were carried out with the minimal STO-3G and split valence $3-21 \mathrm{G}$ basis sets $22-25$ with the GAUSSIAN 82 program system ${ }^{27}$ running on a VAX 8530 computer. The STO-3G basis 

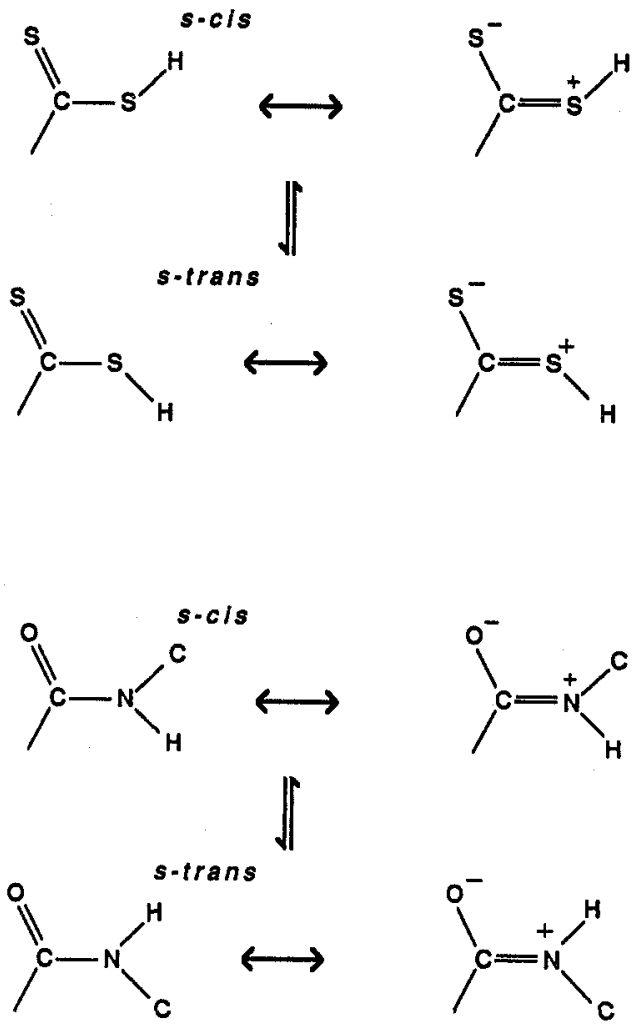

Figure 2. $\mathrm{s}-\mathrm{Cis} / \mathrm{s}-$ trans isomerism about $\mathrm{C}-\mathrm{N}$ (amide) and $\mathrm{C}-\mathrm{S}$ bonds. The herein adopted nomenclature of isomers about the $\mathrm{C}-\mathrm{N}$ (amide) bond differs from that frequenctly used by peptide chemists, the s-cis and s-trans forms corresponding, respectively, to those conformations peptide chemists usually refer to as trans and cis forms.

set was used to search the conformational space in order to find approximate geometries of the most relevant conformers.

Molecular geometries were fully optimized by the force gradient method with analytical gradient: ${ }^{28}$ the bond lengths within $\approx 1 \mathrm{pm}$, the bond angles within $\approx 0.1^{\circ}$. In all calculations the maximum residual force on each internal coordinate was set up to $3 \times 10^{-4}$ hartree bohr ${ }^{-1}$ or hartree radian $^{-1}$.

Molecular graphics were generated from the 3-21G optimized geometries with the MOLECULAR EDITOR program ${ }^{29}$ on an Apple Macintosh computer.

\section{Results and Discussion}

The existence of a large number of possible conformational states for the $N$-formylglycine dithio acid molecule is easily predicted on the basis of simple stereochemical principles, when the four internal axes of rotation of the molecule $(\mathrm{O}=\mathrm{C}-\mathrm{N}-\mathrm{C}$, $\mathrm{C}-\mathrm{N}-\mathrm{C}-\mathrm{C}, \mathrm{N}-\mathrm{C}-\mathrm{C}=\mathrm{S}$, and $\mathrm{S}=\mathrm{C}-\mathrm{S}-\mathrm{H}$ ) are taken into account. Internal rotation about $\mathrm{C}-\mathrm{N}$ (amide) or $\mathrm{C}-\mathrm{S}$ bonds leads to s-cis/s-trans isomerism (Figure 2 ), as these bonds have a considerable double bond character. On the other hand, although internal rotations about $\mathrm{N}-\mathrm{C}_{\alpha}$ or $\mathrm{C}_{\alpha}-\mathrm{C}$ bonds obviously lead to several conformers, it is not possible to characterize such forms a priori, in view of the different intramolecular interactions that are known to be operating within the $\mathrm{NHCH}_{2} \mathrm{CS}_{2}$ fragment. ${ }^{7-9}$ Thus, we performed initially a detailed examination of the molecular potential energy surface, by using the STO-3G basis set, to search for energy minima. While the results obtained at the STO-3G level gave rise to several anomalies due to the reduced

(26) Tonge, P. J.; Menard, R.; Storer, A. C.; Carey, P. R. J. Am. Chem. Soc. In press.

(27) Binkley, J. S.; Frisch, M. J.; Defrees, D. J.; Raghavachari, K.; Whiteside, R. A.; Schlegel, H. B.; Fluder, E. M.; Pople, J. A. Gaussian 82, Carnegie-Mellon University, Pittsburgh, PA, 1983.

(28) Schlegel, H. B. Ph.D. Thesis, Queen's University, Kingston, Ontario, Canada, 1975.

(29) Wargo, R.; McFerren, D.; Sterling, J. A.; Mishra, K.; Smith A. L. MOLECULAR EDITOR (Version 1.1), Department of Chemistry, University of Drexel, USA, 1987. size of the basis set, these calculations allowed us to undertake the main body of calculations, carried out by using the larger 3-21G basis set, within restricted regions of the molecular configurational space. This allowed the computational time to be kept within tractable bounds.

The STO-3G potential energy surface mapping was performed by varying systematically the $\mathrm{C}-\mathrm{N}-\mathrm{C}-\mathrm{C}$ and $\mathrm{N}-\mathrm{C}-\mathrm{C}=\mathrm{S}$ dihedral angles and performing full geometry optimization for each combination of these angles. As our previous studies on simple dithio acids and dithio esters ${ }^{15,17,18}$ demonstrated, a s-cis $\mathrm{S}=\mathrm{C}-\mathrm{S}-\mathrm{R}(\mathrm{R}=\mathrm{H}$ or alkyl) conformer is always more stable than s-trans by more than $12 \mathrm{~kJ} \mathrm{~mol}^{-1}$. Therefore, the conformation about the $\mathrm{C}-\mathrm{S}$ bond was fixed in the s-cis form in all calculations. In addition, a s-cis $\mathrm{O}=\mathrm{C}-\mathrm{N}-\mathrm{C}$ axis is always given as input data for geometry optimization as s-trans $\mathrm{O}=\mathrm{C}-\mathrm{N}-\mathrm{C}$ axes are rare exceptions in peptide bonds (the experimental value for $\Delta E_{\text {(s-trans)-(s-cis) }}$ is $\approx 10 \mathrm{~kJ} \mathrm{~mol}^{-130,31}$ ).

Despite these restrictions, the STO-3G calculations gave rise to seven different "conformers" (Figure 3), five of these corresponding to degenerate conformational states, which increase the total number of energy minima to 12 . The two nondegenerate forms are planar ( $C_{s}$ point group) with $\mathrm{O}=\mathrm{C}-\mathrm{N}-\mathrm{C}, \mathrm{C}-\mathrm{N}-$ $\mathrm{C}-\mathrm{C}$, and $\mathrm{S}=\mathrm{C}-\mathrm{C}-\mathrm{N}$ dihedral angles equal to $\left(0.0^{\circ}, 180.0^{\circ}\right.$, $\left.0.0^{\circ} ; \mathrm{I}\right)$ and $\left.0.0^{\circ}, 180.0^{\circ}, 180.0^{\circ} ; \mathrm{II}\right)$. The remaining five distinct "conformers" ( $C_{1}$ point group) are characterized by the following dihedral angles: $\left(18.6^{\circ}, 77.0^{\circ}, 3.6^{\circ}\right.$; III $),\left(-17.8^{\circ}, 158.1^{\circ}, 134.0^{\circ}\right.$; IV), $\left(-15.3^{\circ},-65.3^{\circ}, 132.5^{\circ} ; \mathrm{V}\right),\left(15.6^{\circ}, 82.9^{\circ}, 173.9^{\circ} ; \mathrm{VI}\right)$, and $\left(17.0^{\circ}, 88.3^{\circ}, 95.7^{\circ}\right.$; VII). Thus, with the exceptions of the $C_{s}$ forms, all the calculated STO-3G structures present a pyramidal amide nitrogen atom, with a nonplanar amide bond. This wrong prediction of the peptide geometry can be ascribed to the small size of the basis set which, in turn, can also lead to the appearance of some artificial minima in the potential energy surface. Simple electronic or stereochemical considerations allow us to conclude that the $C_{s}$ "conformer" II and the last two STO-3G $C_{1}$ forms (VI and VII) possess unfavorable interactions $\left(\mathrm{C}=\mathrm{O} \cdots \mathrm{S}_{(\text {thiol })}\right.$ or NH...SH; see Figure 3). In fact, they are high energy forms that together should correspond to less than $1 \%$ of the total population, at $298 \mathrm{~K}$.

Thus, we initiated the $3-21 \mathrm{G}$ calculations beginning with the optimized geometries of the four most stable STO-3G "conformers" (I, III, IV, and V). Two of them (IV and V) converged to the same structure upon optimization at the 3-21G level, and this structure corresponds closely to the conformer B characterized by experimental means ${ }^{7-9}$ (Table I). Upon optimizing form I shown in Figure 3, the resulting structure was the five-membered $\mathrm{H}$-bonded ring structure known as $\mathrm{C}_{5}$, which had been proposed on the basis of FTIR studies. ${ }^{9}$ The remaining form (III) converged to a structure similar to the A conformer, which had also been characterized previously by experimental means. ${ }^{7}$ Thus, the three conformational states found at this level of calculation correlate with the experimentally determined conformers.

The most stable conformer, obtained from optimization of STO-3G IV and V forms, is clearly a B-type conformer, with the nitrogen and the sulfur thiol atoms in close contact, though the $\mathrm{C}-\mathrm{C}-\mathrm{N}-\mathrm{C}$ dihedral angle differs somewhat from the $\mathrm{X}$-ray crystallographic values found for $N$-acylglycine dithio esters. ${ }^{7-9}$ The remaining two conformers, the A-type and $C_{5}$ forms, are 2.0 and $5.8 \mathrm{~kJ} \mathrm{~mol}^{-1}$ higher in energy than the $\mathrm{B}$ conformer, respectively. As was found in the case of the most stable form, the $\mathrm{C}-\mathrm{C}-\mathrm{N}-\mathrm{C}$ dihedral angle of the A conformer differs significantly from the $\mathrm{N}$-acylglycine dithioesters $\mathrm{X}$-ray derived values ${ }^{7}$ (see Table I). In both forms (A and B), the calculated C-C-N-C angle for $N$-formylglycine dithio acid differs from those found in crystalline dithio esters as the distance between the carbonyl oxygen atom and one of the methylene hydrogen atoms is reduced. Together with an increased electronic density between these atoms,

(30) Fersht, A. Enzyme Structure and Mechanism, 2nd Ed.; W. H. Freeman and Company: New York, NY, 1985; pp 8, 9, and references herein mentioned.

(31) Jorgensen, W. L.; Gao, J. J. Am. Chem. Soc. 1988, 110, 4212. 


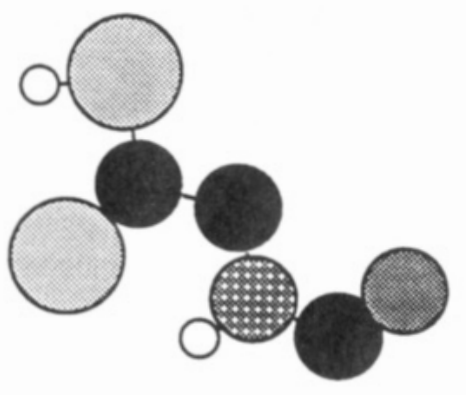

I

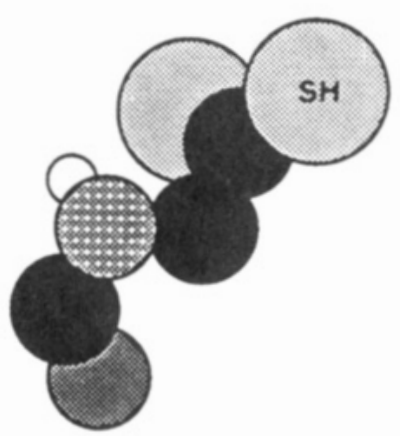

IV

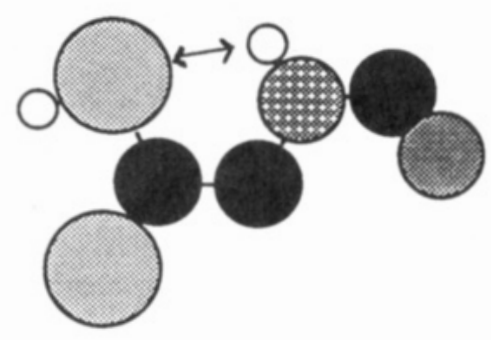

II

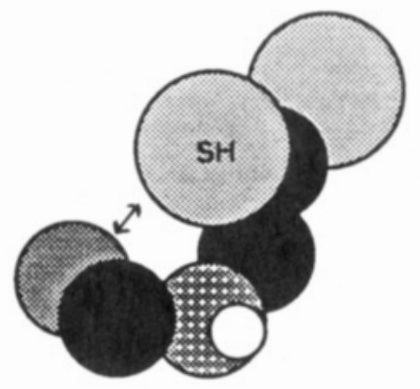

v

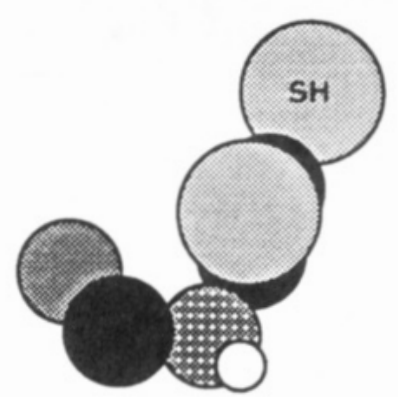

III

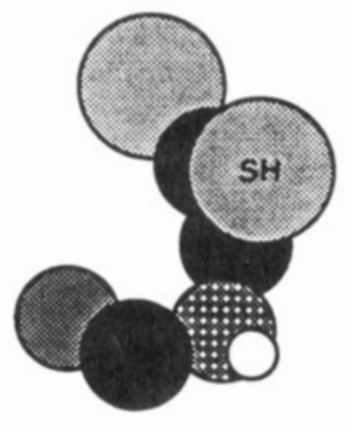

U

VII

Figure 3. STO-3G calculated energy minima of $\mathrm{N}$-formylglycine dithio acid. The arrows indicate unfavorable electronic or stereochemical interactions that occur in forms II, VI, and VII.

the change in the $\mathrm{C}-\mathrm{C}-\mathrm{N}-\mathrm{C}$ angle points to the existence of an intramolecular hydrogen bond, involving the formation of a $\mathrm{O}=$ $\mathrm{C}-\mathrm{N}-\mathrm{C}-\mathrm{H}$ five-member ring. In the case of $\mathrm{N}$-acylglycine dithio esters in the crystalline state, the carbonyl oxygen atom is hydrogen-bonded to the amide hydrogen atom of an adjacent molecule, ${ }^{7-9}$ thus preventing the formation of an intramolecular hydrogen bond and leading to a different, probably more relaxed, $\mathrm{C}-\mathrm{C}-\mathrm{N}-\mathrm{C}$ angle. Despite the differences in the values of the $\mathrm{C}-\mathrm{C}-\mathrm{N}-\mathrm{C}$ dihedral angles, the general agreement between the calculated and X-ray geometries is quite good for both A and B forms (see Table I).

In agreement with experiment, ${ }^{7-9}$ the $3-21 \mathrm{G}$ calculations yield approximately planar amide linkages. The mesomerism associated with this molecular fragment is clearly evidenced by the relative values of the $\mathrm{C}(=\mathrm{O})-\mathrm{N}$ and $\mathrm{N}-\mathrm{C}$ bond lengths, the first being shorter by $\approx 9 \mathrm{pm}$, in both cases. The calculated C-S bond lengths are longer than those determined experimentally. This overestimation of $\mathrm{C}-\mathrm{S}$ bond lengths by the $3-21 \mathrm{G}$ basis set was shown to be a general trend, ${ }^{15-18}$ and correction factors of 0.98 and 0.95 for $\mathrm{C}=\mathrm{S}$ and $\mathrm{C}-\mathrm{S}$ distances, respectively, have been tentatively proposed ${ }^{18}$ to provide a better agreement with experimental values. By using these correction factors, the $\mathrm{C}-\mathrm{S}$ distances $(\mathrm{pm})$ in $N$-formylglycine dithio acid become form B, C $=\mathrm{S} 162.6, \mathrm{C}-\mathrm{S}$ 171.0; form $\mathrm{A}, \mathrm{C}=\mathrm{S} 161.9, \mathrm{C}-\mathrm{S} 172.0$; and form $\mathrm{C}_{5}, \mathrm{C}=\mathrm{S} 162.5$, $\mathrm{C}-\mathrm{S}$ 171.8. For both $\mathrm{A}$ and $\mathrm{B}$ forms, these corrected values strongly improve the agreement with X-ray results.

Large differences in the bond angles occur in the $\mathrm{RC}(=\mathrm{O}) \mathrm{N}$ group, where $\mathrm{R}$ is $\mathrm{H}$ as in the case of $\mathrm{N}$-formylglycine dithio acid compared to when $\mathrm{R}$ is one of the more complex groups found in all the previously studied dithio esters. In particular, for $\mathrm{N}$-formylglycine dithio acid, the $\mathrm{R}-\mathrm{C}-\mathrm{N}$ angle is larger and the $\mathrm{O}=\mathrm{C}-\mathrm{N}$ angle is smaller than the experimental values for dithio esters, while the $\mathrm{R}-\mathrm{C}=\mathrm{O}$ angle does not change appreciably. When $\mathrm{R}$ is a hydrogen atom, the $\mathrm{R} \cdots \mathrm{N}$ steric repulsion is practically absent, and the $\mathrm{R}-\mathrm{C}-\mathrm{N}$ angle is reduced; the change in this angle is compensated by an increase in the $\mathrm{O}=\mathrm{C}-\mathrm{N}$ angle. In fact, the third correlated angle $\left(\mathrm{R}-\mathrm{C}=\mathrm{O}=360^{\circ}-(\mathrm{R}-\mathrm{C}-\right.$ $\mathrm{N})-(\mathrm{O}=\mathrm{C}-\mathrm{N}))$ has a reduced sensitivity to substituent or conformational changes as has already been well-established. ${ }^{17,18}$
By comparing the structural changes associated with the $\mathrm{A} \rightarrow$ $\mathrm{B}$ conversion, the following trends emerge: (i) The $\mathrm{C}=\mathrm{O}$ bond becomes shorter, while the $\mathrm{C}(=\mathrm{O})-\mathrm{N}$ bond is lengthened. These changes indicate a reduced electronic delocalization within the amide group in the B form and are associated with a lack of relative importance of the $\mathrm{C}\left(-\mathrm{O}^{-}\right)=\mathrm{N}^{+}$canonical form in this conformer.

(ii) The $\mathrm{C}=\mathrm{S}$ bond length increases, while the $\mathrm{C}-\mathrm{S}$ bond decreases, thus pointing to an increased electronic delocalization in the dithioester group in the B form. This confirms earlier crystallographic findings that the $\mathrm{C}-\mathrm{S}$ bond is slightly shorter in $\mathrm{B}$ conformer glycine dithio esters ${ }^{7,8}$ and suggests that this linkage, which is the one cleaved during the hydrolysis of dithioacyl papains, is strengthened in B conformer acyl enzymes.

(iii) The geometry of the $\mathrm{N}-\mathrm{C}-\mathrm{C}=\mathrm{S}$ fragment adjusts in a way to satisfy the steric requirements associated with the $\mathrm{N}$. - $\mathrm{S}_{\text {(thiol) }}$ contact, the $\mathrm{C}-\mathrm{N}$ bond is lengthened, the $\mathrm{N}-\mathrm{C}-\mathrm{C}$ and $\mathrm{C}-\mathrm{C}-\mathrm{S}$ angles are opened and the $\mathrm{C}-\mathrm{C}=\mathrm{S}$ angle becomes smaller. These changes, taken with the changes in dihedral angles,

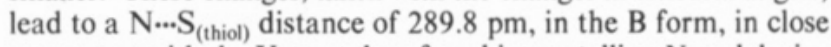
agreement with the $\mathrm{X}$-ray values found in crystalline $\mathrm{N}$-acylglycine dithio esters (284.6-293.0 pm, see Table I).

As it has been pointed out elsewhere, ${ }^{7}$ the N...S nonbonded distance is approximately $45 \mathrm{pm}$ shorter than the sum of the van der Waals radii (335 pm), a reduction possibly resulting from a $\mathrm{N}$... $\mathrm{S}_{\text {(thiol) }}$ attraction. The atoms $\mathrm{S}_{(\text {thiol) }}, \mathrm{H}_{\text {(thiol) }}$, and $\mathrm{N}$ lie nearly in a straight line, with a N...S-H angle of $154.4^{\circ}$, thus matching Rosenfield's et al. ${ }^{32}$ geometrical criterion for a nucleophilic nitrogen approaching an electrophilic sulfur. Hence, the ab initio calculations are in agreement with the proposed interpretation of the $\mathrm{N}$... $\mathrm{S}_{(\text {thiol })}$ interaction based on experimental data. ${ }^{7-9}$ In addition, the results of Mulliken populational analysis indicate that this interaction involves predominantly the nitrogen $2 \mathrm{p}$ orbital approximately perpendicular to the amide linkage and the sulfur $3 p$ orbital nearly parallel to that orbital. Essentially, this is an S-type interaction, which may also involve sulfur $3 \mathrm{~d}$ orbitals as

(32) Rosenfield, R. E.; Parthasarathy, R.; Dunitz, J. D. J. Am. Chem. Soc. $1977,99,4860$. 
Table I. 3-21G Calculated Energies and Geometries of A, B, and $C_{5}$ Conformers of $N$-Formylglycine Dithio Acid and Experimental Geometries for A and B Forms of Crystalline $N$-Acylglycine Dithio Esters $^{a}$

\begin{tabular}{|c|c|c|c|c|c|}
\hline \multirow[b]{2}{*}{ parameter } & \multicolumn{2}{|c|}{ form $A$} & \multicolumn{2}{|r|}{ form $B$} & \multirow[b]{2}{*}{$3-21 G$} \\
\hline & $3.21 \mathrm{G}$ & exptl & $3-21 G$ & exptl & \\
\hline $\mathrm{C}-\mathrm{H}($ formyl $)$ & 108.1 & & 108.1 & & 108.2 \\
\hline $\mathrm{C}=\mathrm{O}$ & 121.3 & 123.0 & 121.2 & $123.1-123.8$ & 121.6 \\
\hline $\mathrm{C}-\mathrm{N}$ & 136.0 & 133.1 & 136.3 & $132.3-134.2$ & 135.1 \\
\hline $\mathrm{N}-\mathrm{H}$ & 99.8 & & 99.8 & & 99.8 \\
\hline $\mathrm{N}-\mathrm{C}$ & 144.1 & 143.9 & 144.9 & $144.1-145.3$ & 144.9 \\
\hline $\mathrm{C}-\mathrm{C}$ & 151.4 & 151.6 & 151.2 & $150.4-152.2$ & 150.4 \\
\hline $\mathrm{C}=\mathrm{S}$ & 165.3 & 161.5 & 165.9 & $161.5-163.5$ & 165.8 \\
\hline $\mathrm{C}-\mathrm{S}$ & 181.1 & 172.7 & 180.0 & $170.0-171.1$ & 180.8 \\
\hline $\mathrm{S}-\mathrm{H}$ & 134.8 & & 134.9 & & 134.8 \\
\hline \multirow[t]{2}{*}{$\mathrm{C}-\mathrm{H}$} & 108.3 & & 108.1 & & 108.6 \\
\hline & 108.5 & & 108.4 & & \\
\hline $\mathrm{H}-\mathrm{C}=\mathrm{O}$ & 122.9 & $120.4^{b}$ & 123.0 & $120.6-122.0^{b}$ & 123.1 \\
\hline $\mathrm{O}=\mathrm{C}-\mathrm{N}$ & 124.4 & 122.2 & 124.3 & $121.1-121.5$ & 123.6 \\
\hline $\mathrm{H}-\mathrm{C}-\mathrm{N}$ & 112.7 & $117.4^{c}$ & 112.7 & $116.5-118.3^{c}$ & 113.3 \\
\hline $\mathrm{H}-\mathrm{N}-\mathrm{C} \Leftrightarrow$ & 119.8 & & 119.7 & & 121.9 \\
\hline $\mathrm{C}-\mathrm{N}-\mathrm{C}$ & 120.6 & 121.5 & 120.9 & $121.1-121.2$ & 119.1 \\
\hline $\mathrm{C}-\mathrm{C}-\mathrm{N}$ & 114.0 & 114.8 & 114.5 & $114.5-115.8$ & 113.1 \\
\hline $\mathrm{C}-\mathrm{C}=\mathrm{S}$ & 125.4 & 124.5 & 121.6 & $119.1-119.8$ & 125.8 \\
\hline $\mathrm{C}-\mathrm{C}-\mathrm{S}$ & 110.4 & 108.7 & 113.9 & $113.5-114.2$ & 110.6 \\
\hline$S=C-S$ & 124.2 & 126.8 & 124.5 & $126.1-127.4$ & 123.6 \\
\hline $\mathrm{C}-\mathrm{S}-\mathrm{H}$ & 97.6 & & 96.8 & & 97.4 \\
\hline \multirow[t]{2}{*}{$\mathrm{H}-\mathrm{C}-\mathrm{C}$} & 108.6 & & 108.0 & & 108.3 \\
\hline & 107.7 & & 107.4 & & \\
\hline$N-(C=0)-H$ & 180.0 & & 180.0 & & 180.0 \\
\hline $\mathrm{O}=\mathrm{C}-\mathrm{N}-\mathrm{H}$ & 174.9 & & -176.8 & & 180.0 \\
\hline $\mathrm{O}=\mathrm{C}-\mathrm{N}-\mathrm{C}$ & -4.4 & -1.1 & 0.5 & $-1.0-6.4$ & 0.0 \\
\hline $\mathrm{C}-\mathrm{C}-\mathrm{N}-\mathrm{C}$ & -109.8 & -86.2 & -114.4 & -76.3 to -97.1 & 180.0 \\
\hline $\mathrm{N}-\mathrm{C}-\mathrm{C}=\mathrm{S}$ & 2.2 & 10.6 & 162.6 & $158.7-171.5$ & 0.0 \\
\hline $\mathrm{N}-\mathrm{C}-\mathrm{C}-\mathrm{S}$ & -178.4 & -171.7 & -18.1 & -10.5 to -22.2 & 180.0 \\
\hline$C-C-S-H$ & 0.0 & & 0.0 & & 0.0 \\
\hline $\mathrm{H}-\mathrm{C}-\mathrm{C}=\mathrm{S}$ & 121.5 & & 38.6 & & 122.5 \\
\hline & -121.6 & & -78.1 & & \\
\hline $\mathrm{N} \cdots \mathrm{S}=$ & 305.8 & 304.3 & & & 304.2 \\
\hline N...S & & & 289.8 & $284.6-293.0$ & \\
\hline $\mathrm{H} \cdot . \mathrm{S}=$ & 300.9 & & & & 255.0 \\
\hline$\Delta E_{\mathrm{X}-\mathrm{B}}{ }^{d}$ & 2.0 & & 0.0 & & 5.8 \\
\hline
\end{tabular}

${ }^{\circ}$ Energies in $\mathrm{kJ} \mathrm{mol}^{-1}$; bond lengths in pm; angles in deg. Experimental data taken from refs 7-9; for B form, the values presented correspond to the observed range of values found in $N$-acylglycine dithio esters. ${ }^{b} \mathrm{C}-\mathrm{C}=\mathrm{O}$ angle. ${ }^{c} \mathrm{C}-\mathrm{C}-\mathrm{N}$ angle. ${ }^{d} \mathrm{X}=\mathrm{A}, \mathrm{B}$, or $\mathrm{C}_{5}$, total energy for B form: $-1035.5542997 E_{\mathrm{h}}\left(1 E_{\mathrm{h}}=2625.5001 \mathrm{~kJ} \mathrm{~mol}^{-1}\right)$.

previously proposed. ${ }^{8}$ The $\theta$ angle defined in ref 8 -the angle between the N...S direction and the normal to the amide plane (the normal being the direction of the amide lone pair)-is calculated to be $\approx 12^{\circ}$, thus being smaller than the corresponding values found in crystalline $N$-acylglycine dithio esters $\left(\approx 20^{\circ} 8\right)$. The occurrence of the above-mentioned $\mathrm{C}=\mathrm{O} \cdot . \mathrm{H}$ intramolecular interaction in the isolated molecule and its absence in crystalline dithio esters can, at least partially, account for this difference in the $\theta$ values.

The detailed molecular structure of a $\mathrm{C}_{5}$-like conformer is now presented for the first time, as none of the $N$-acylglycine dithio esters already studied was found to crystallize in this form. The structural changes associated with the $A \rightarrow C_{5}$ isomerization can be summarized as follows.

(i) The molecular skeleton in the calculated $\mathrm{C}_{5}$ conformer is planar, the $\mathrm{C}-\mathrm{C}-\mathrm{N}-\mathrm{C}$ axis being rotated by $\approx 90^{\circ}$ from its position in the $\mathrm{A}$ form. This internal rotation allows the formation of a hydrogen bond between the $\mathrm{NH}$ and $\mathrm{S}_{(\text {thiono) }}$ atoms in a fivemembered ring. These results confirm the conformational model proposed to interpret FTIR spectroscopic data of $\mathrm{N}$-acylglycine dithio esters in $\mathrm{CCl}_{4}$ solution. ${ }^{9}$

(ii) The $\mathrm{C}=\mathrm{S}$ bond increases, while the $\mathrm{C}-\mathrm{S}$ bond keeps nearly equal to that found in the $A$ form. These changes clearly indicate the release of electronic density from the $S_{(\text {thiono) }}$ atom to other regions of the molecule, and the best acceptor candidate is the

(33) Issued as NRCC No. 31936.
Table II. 3-21G Calculated Atomic Charges and Dipole Moments of $\mathrm{A}, \mathrm{B}$, and $\mathrm{C}_{5}$ Conformers of $N$-formylglycine Dithio Acid ${ }^{a}$

\begin{tabular}{crrr}
\hline atom & \multicolumn{1}{c}{ form A } & form B & \multicolumn{1}{c}{ form $\mathrm{C}_{3}$} \\
\hline & \multicolumn{3}{c}{ charges $/ \mathrm{e}$} \\
$\mathrm{H}$ & 0.211 & 0.217 & 0.213 \\
$\mathrm{C}$ & 0.633 & 0.633 & 0.626 \\
$\mathrm{O}$ & -0.605 & -0.597 & -0.614 \\
$\mathrm{~N}$ & -0.877 & -0.892 & -0.903 \\
$\mathrm{H}$ & 0.375 & 0.371 & 0.399 \\
$\mathrm{C}$ & -0.167 & -0.165 & -0.130 \\
$\mathrm{H}$ & 0.320 & 0.328 & 0.291 \\
$\mathrm{H}$ & 0.274 & 0.284 & 0.291 \\
$\mathrm{C}$ & -0.677 & -0.689 & -0.695 \\
$\mathrm{~S}$ & 0.165 & 0.148 & 0.157 \\
$\mathrm{~S}$ & 0.220 & 0.252 & 0.242 \\
$\mathrm{H}$ & 0.124 & 0.112 & 0.124 \\
& & $|\vec{\mu}| / \mathrm{D}$ & \\
\multicolumn{5}{c}{3.23} & 3.98 & 2.33 \\
\hline $\mathrm{a}$ & $1.6021892 \times 10^{-19} \mathrm{C} ; 1 \mathrm{D}=(1 / 3) \times 10^{-2} \mathrm{~cm}$.
\end{tabular}

NH group. In fact, results of Mulliken populational analysis confirm this, indicating a significant electronic density in the $\mathrm{H} \cdots \mathrm{S}=\mathrm{C}$ region of the $\mathrm{C}_{5}$ conformer.

(iii) The intramolecular $\mathrm{NH} \cdots \mathrm{S}=\mathrm{C}$ interaction is also reflected in the opening of the $\mathrm{C}-\mathrm{N}-\mathrm{H}$ angle as well as in the reduction in the $\mathrm{N}-\mathrm{C}-\mathrm{C}$ angle that bring the $\mathrm{H}$ and $\mathrm{S}_{\text {(thiono) }}$ atoms to within about $255 \mathrm{pm}$ (the sum of the van der Waals radii is $285 \mathrm{pm}$ ) and give rise to the formation of a hydrogen bond.

(iv) The $\mathrm{C}=\mathrm{O}$ bond increases, while the $\mathrm{C}(=\mathrm{O})-\mathrm{N}$ bond is reduced. In the present work, these bond lengths reach their maximum and minimum values, respectively, for this conformer, thus indicating that the electron delocalization within the amide moiety is optimized for this form.

Another important and somewhat surprising result of our calculations is the finding that the $\mathbf{N} \cdots \mathrm{S}_{(\text {thiono) }}$ interaction does not play any important role in the $\mathrm{A}$ conformer, in disagreement with suggestions of the work on $N$-acylglycine dithio esters. ${ }^{4-7}$ However, the $\mathbf{N} \cdots \mathrm{S}_{(\text {thiono) }}$ interaction should be considerably weaker than the $\mathbf{N}$... $\mathrm{S}_{\text {(thiol) }}$ contact. In fact, the calculated N... $\mathrm{S}_{\text {(thiono) }}$ distance in $N$-formylglycine dithio acid (form A) is $305.8 \mathrm{pm}$, a value similar both to that calculated for the $C_{5}$ conformer $(304.2 \mathrm{pm}$ ) and to those found in dithio ester molecules ${ }^{7}$ but considerably larger than the $\mathrm{N} \cdots \mathrm{S}_{(\text {thiol })}$ distance in B-like conformers $(\approx 289$ $\mathrm{pm})$. The most relevant piece of data supporting the lack of the $\mathrm{N} \cdot . . \mathrm{S}_{\text {(thiono) }}$ interaction in the A conformer is given by the absence of significant electronic density between these atoms. While the addition of d-polarization functions on both nitrogen and sulfur atoms might give rise to an increase of the electronic density in this region of the molecule, it is unlikely that their inclusion will change the qualitative conclusions.

In Table II we present the 3-21G calculated atomic charges and dipole moments for $\mathrm{A}, \mathrm{B}$, and $\mathrm{C}_{5}$ forms. It is well-known that the calculated charge distribution depends very much upon this basis set used in constructing the molecular wave function, even for basis sets of comparable quality. Moreover, the Mulliken population analysis has its intrinsic limitations resulting from the equipartioning of the overlap density between atoms. While our experience has demonstrated that the charges of sulfur atoms in a dithiocarbonyl group are not appropriately calculated in the absolute terms at this level of calculation, ${ }^{17}$ it has been shown that conformational changes predicted with use of the 3-21G basis set and Mulliken population analysis are significant and valuable for examining different kinds of intramolecular interactions. ${ }^{15-18}$ On the other hand, dipole moments are usually well-evaluated at this level of calculations, despite a well-known trend to overestimation. ${ }^{15-18}$

In agreement with the experimental data on $N$-acylglycine dithio esters, ${ }^{4}$ the calculations reveal that the most polar form corresponds to the $B$ conformer and the least polar form to the $C_{5}$ form. Thus, in a polar solvent, the $B$ form is stabilized with respect to the $A$ form, and the $\Delta E_{\mathrm{A}-\mathrm{B}}$ increases. Considering this effect, the 3-21G calculated $\Delta E_{\mathrm{A}-\mathrm{B}}\left(2.0 \mathrm{~kJ} \mathrm{~mol}^{-1}\right)$ seems to be a good estimate of the actual energy difference between these conformers for the 
isolated molecule, since this value is slightly smaller than the range of energy $(\Delta H)$ difference found to various $N$-acylglycine dithio derivatives in $\mathrm{CH}_{3} \mathrm{CN} / \mathrm{H}_{2} \mathrm{O}$ solutions $\left(2.7-4.2 \mathrm{~kJ} \mathrm{~mol}^{-1}{ }^{4}\right)$.

The main conclusions emerging from the comparison of atomic charges in different conformers are summarized below and reinforce the importance of both $\mathrm{NH} \cdots \mathrm{S}_{(\text {thiono) }}$ hydrogen bonding in the $\mathrm{C}_{5}$ form and the $\mathrm{N}$... $\mathrm{S}_{(\text {thiol) }}$ contact in the $\mathrm{B}$ form.

(i) The amide hydrogen atom in the $\mathrm{C}_{5}$ form acquires an increased positive charge, resulting from the involvement of this atom in the $\mathrm{NH}$... $\mathrm{S}_{\text {(thiono) }}$ hydrogen bond. (ii) The $\mathrm{N}$ and $\mathrm{S}$ atoms are involved in different processes of electron sharing in the various conformers (mesomerism, nonbonded contacts, and hydrogen bonding). Thus, their charge cannot be taken as a single measure of a particular effect. However, the larger negative overall charge within the CSSH group in the B conformer clearly reflects the nitrogen-to-sulfur charge release due to the $\mathbf{N} \ldots \mathrm{S}_{(\text {thiol }}$ interaction.

(iii) The changes in the atomic charges within the $\mathrm{C}(=\mathrm{O}) \mathrm{N}$ fragment, going from the A to B form, relates to the greater importance of mesomerism in the $A$ conformer, involving the $\mathrm{C}\left(-\mathrm{O}^{-}\right)=\mathrm{N}^{+}$canonical form. It should be pointed out that this increased delocalization in the $\mathrm{A} \mathrm{C}(=0) \mathrm{N}$ moiety can be considered as a factor contributing to the reduced importance of the $N$... $S_{\text {(thiono) }}$ interaction in form A, as compared with the $N$... $S_{(\text {thiol) }}$ interaction in form $B$.

\section{Conclusion}

The calculations emphasize a remarkable similarity between molecular properties of $N$-formylglycine dithio acid and those of $\mathrm{N}$-acylglycine dithio esters in the condensed phase. In particular, in molecules possessing a $\mathrm{C}=\mathrm{O}) \mathrm{NHCH}_{2} \mathrm{CS}_{2}$ fragment, the importance of the $\mathrm{N}$... $\mathrm{S}_{(\mathrm{thiol})}$ contact in $\mathrm{B}$ forms was reinforced. The theoretical evidence for a $\mathrm{C}_{5}$-type conformer provides support for the existence of such a species which heretofore had been inferred on the base of FTIR data alone.

The results of the calculations establish a solid theoretical support for the previously proposed nature of the $N$... $S_{(\text {thiol) }}$ interaction, clearly indicating an electronic charge release from the $N$ to the $S_{(t h i o l)}$ atom in the B conformer, which perturbs the electron distribution in the peptide and dithio ester groups. This in turn demonstrates how the $\mathbf{N} \cdots \mathrm{S}_{(\text {thiol) }}$ contact can act as a conduit which can transmit electronic effects from the peptide to the dithio ester group-and may provide part of the explanation for the differential rate constants of deacylation in para-substituted $N$-benzoylglycine dithioacyl papains. ${ }^{12}$ An important point here is that the N...S contact appears to shorten and hence strengthen the $\mathrm{C}-\mathrm{S}$ single bond-which is the bond which has to be broken in the deacylation step. The calculations are fully consonant with the crystallographic results that the $\mathrm{C}-\mathrm{S}$ bond is slightly shorter in B conformers ( $N$-acetylglycine, ${ }^{7} N$-benzoylglycines, ${ }^{8}$ $170.0-171.1 \mathrm{pm})$ than in A conformers $(N-(p$-nitrobenzoyl)glycine ethyl dithio ester, $\left.{ }^{7} 172.7 \mathrm{pm}\right)$. The issue of the stabilization of the B conformer dithioacyl papain via the N...S contact is taken up in ref 26 where it is used to account, at least in part, for kinetic factors in the deacylation step.

Acknowledgment. R.F. and J.J.C.T.-D. acknowledge the computational assistence provided by the Centro de Informática da Universidade de Coimbra and financial support from the Instituto Nacional de Investigação Cientifica, Portugal. R.F. also thanks Fundação Calouste Gulbenkian for a grant that partially covered his short stay at NRCC, when this work was still going on.

Registry No. $\mathrm{OHCNHCH}{ }_{2} \mathrm{CSSH}, 131904-36-4$.

\title{
Substituted Ethylene Dications: Planar or Perpendicular?
}

\author{
Gernot Frenking \\ Contribution from the Fachbereich Chemie, Universität Marburg, Hans-Meerwein-Strasse, \\ D-3550 Marburg, West Germany. Received July 25, 1990
}

\begin{abstract}
Neutral and doubly charged substituted ethylene dications $\mathrm{C}_{2} \mathrm{X}_{2} \mathrm{Y}_{2}$ are theoretically studied by use of ab initio quantum theoretical methods. Planar geometries are predicted for the dications $\mathrm{C}_{2} \mathrm{~F}_{4}{ }^{2+}, \mathrm{C}_{2}(\mathrm{OH})_{4}{ }^{2+}, \mathrm{C}_{2} \mathrm{H}_{2}\left(\mathrm{NH}_{2}\right)_{2}{ }^{2+}$, and $\mathrm{C}_{2}(\mathrm{OH})_{2}\left(\mathrm{NH}_{2}\right)_{2}{ }^{2+}$, while twisted structures are calculated for $\mathrm{C}_{2} \mathrm{H}_{4}{ }^{2+}, \mathrm{C}_{2}\left(\mathrm{NH}_{2}\right)_{4}{ }^{2+}$, and $\mathrm{C}_{2}(\mathrm{SH})_{4}{ }^{2+}$. The results are explained with molecular orbital arguments. Substituents $\mathrm{X}$ with lone-pair orbitals strongly donate electronic charge into the formally empty $\mathrm{C}(\pi)$ orbital of $\mathrm{C}_{2} \mathrm{X}_{4}{ }^{2+}$, yielding partial $\mathrm{CX}$ double bonds. If $\mathrm{X}$ is a first-row atom, conjugation of the resulting double bonds causes a planar geometry as energy minimum form if steric repulsion of the vicinal groups is absent. The experimentally observed twisted geometry of the bromo and chloro salts of $\mathrm{C}_{2}\left(\mathrm{NH}_{2}\right)_{4}{ }^{2+}$ cannot be considered as validation that $\mathrm{C}_{2} \mathrm{H}_{4}{ }^{2+}$ has a perpendicular energy minimum geometry.
\end{abstract}

\section{Introduction}

Double ionization of neutral $\left(D_{2 h}\right)$ ethylene yields $\mathrm{C}_{2} \mathrm{H}_{4}{ }^{2+}$, which has a theoroetically predicted ${ }^{1,2}$ twisted $\left(D_{2 d}\right)$ geometry. The planar form of $\mathrm{C}_{2} \mathrm{H}_{4}{ }^{2+}$ is a transition state for the rotation around the $\mathrm{CC}$ bond, $\sim 30 \mathrm{kcal} / \mathrm{mol}$ higher in energy than the perpendicular minimum. ${ }^{1,2}$ The strong preference of the ethylene dication for a twisted geometry has been explained by hyperconjugation of the $\mathrm{CH}$ bonds. ${ }^{1} \mathrm{C}_{2} \mathrm{H}_{4}{ }^{2+}$ has been observed in the gas phase, ${ }^{3}$ but an experimental validation for the theoretically predicted

(1) Lammertsma, K.; Barzaghi, M.; Olah, G. A.; Pople, J. A.; Kos, A. J.; Schleyer, P. v. R. J. Am. Chem. Soc. 1983, 105, 5252.

(2) Frenking, G.; Koch, W.; Schwarz, H. J. Comput. Chem. 1986, 7, 406.

(3) Benoit, C.; Horsley, J. A. Mol. Phys. 1975, 30, 557. twisted geometry is still missing. The high energy needed to remove two electrons from ethylene prevents the preparation of a salt compound of $\mathrm{C}_{2} \mathrm{H}_{4}{ }^{2+}$ that would allow the measurement of its geometry. In order to prove the theoretical prediction that $\mathrm{C}_{2} \mathrm{H}_{4}{ }^{2+}$ has a perpendicular geometry, Bock et al. ${ }^{4}$ recently prepared the bromo and chloro salts of tetrakis(dimethylamino)ethylene dication $\mathrm{C}_{2}(\mathrm{NMe})_{4}{ }^{2+}$ and measured the geometries by $\mathrm{X}$-ray diffraction. Indeed, they found that the geometry of $\mathrm{C}_{2}$ (NMe $)_{4}^{2+}$ exhibits twisting angles $\omega$ around the $\mathrm{CC}$ bond of $76^{\circ}$ (chloro salt) and $67^{\circ}$ (bromo salt). ${ }^{4}$ The experimental results were supported by $\mathrm{MNDO}^{5}$ calculations that predict a twisting angle

(4) Bock, H.; Ruppert, K.; Merzweiler, K.; Fenske, D.; Goesman, H. Angew. Chem. 1989, 101, 1715. 